Castaman, AS \& Szatkoski, E. (2020). Distance education in the context of professional and technological education: considerations in pandemic times. Research, Society and Development, 9(7): 1-27, e491974399.

\title{
Educação a distância no contexto da educação profissional e tecnológica: considerações em tempos de pandemia
}

\section{Distance education in the context of professional and technological education: considerations in pandemic times \\ Educación a distancia en el contexto de la educación profesional y tecnológica: consideraciones en tiempos pandémicos}

Recebido: 10/05/2020 | Revisado: 13/05/2020 | Aceito: 14/05/2020 | Publicado: 23/05/2020

\section{Ana Sara Castaman}

ORCID: https://orcid.org/0000-0002-5285-0694 Instituto Federal de Educação, Ciência e Tecnologia do Rio Grande do Sul, Brasil

E-mail: ana.castaman@sertao.ifrs.edu.br

Elenice Szatkoski

ORCID: https://orcid.org/0000-0001-5169-1428

Instituto Federal de Educação, Ciência e Tecnologia do Amazonas, Brasil

E-mail: elenice.szatkoski@ifam.edu.br

\section{Resumo}

Considerando a pandemia COVID-19 que assola o mundo atualmente o presente artigo tem por objetivo conhecer as definições e os fundamentos da Educação a Distância (EaD), com a finalidade de examinar o embasamento legal e a adoção do ensino a distância no Instituto Federal de Educação, Ciência e Tecnologia do Amazonas (IFAM) - Campus Parintins. Para tanto, a partir de uma abordagem qualitativa, do tipo bibliográfica está dividido em 03 (três) partes: a) apresenta os procedimentos metodológicos; b) discute os conceitos e os documentos regulatórios da $\mathrm{EaD}$ no Brasil; c) trata da legislação e da adoção do ensino a distância no IFAM - Campus Parintins. Conclui-se que o atual cenário de Pandemia, proporcionou a retomada do debate e os inúmeros desafios e a presença de resistências que permeiam a EaD no país, em especial, na rede federal de ensino que se ocupa com a Educação Profissional e Tecnológica. Ainda, este momento conduziu a avanços reflexivos que fomentam a necessidade imediata de se promover condições para que esta modalidade possa de fato vir a 
ser no país a saída para oferta de Educação para vencer os desafios pós pandemia do COVID19.

Palavras-chave: Educação a distância; Pandemia; Educação profissional e tecnológica.

\begin{abstract}
Considering the pandemic COVID-19 currently plaguing the world this article aims to understand the definitions and fundamentals of Distance Education (DE), with the purpose of examining the legal basis and the adoption of distance learning at the Federal Institute of Education, Science and Technology of Amazonas (IFAM) - Campus Parintins. For this purpose, based on a qualitative approach, the bibliographic type is divided into 03 (three) parts: a) it presents the methodological procedures; b) discusses the concepts and regulatory documents of distance education in Brazil; c) deals with the legislation and the adoption of distance learning at IFAM - Campus Parintins. It is concluded that the current scenario of Pandemic provided the resumption of the debate and the countless challenges and the presence of resistances that permeate DE in the country, especially in the federal education network that deals with Professional and Technological Education. Still, this moment has led to reflexive advances that foster the immediate need to promote conditions so that this modality can in fact come to be in the country to overcome the post-pandemic challenges of
\end{abstract} COVID-19.

Keywords: Distance education; Pandemic; Professional and technological education.

\title{
Resumen
}

Considerando la pandemia COVID-19 que actualmente afecta al mundo, este artículo tiene como objetivo es comprender las definiciones y fundamentos de la Educación a Distancia (DE), con el propósito de examinar la base legal y la adopción de la educación a distancia en el Instituto Federal de Educación, Ciencia y Tecnología de Amazonas (IFAM) - Campus Parintins. Por lo tanto, desde un enfoque cualitativo, el tipo bibliográfico se divide en 03 (tres) partes: a) presenta los procedimientos metodológicos; b) discute los conceptos y documentos reglamentarios de la educación a distancia en Brasil; c) aborda la legislación y la adopción de la educación a distancia en IFAM - Campus Parintins. Se concluye que el escenario actual de la pandemia proporciono la reanudación del debate y los innumerables desafíos y la presencia de resistencias que impregnan la DE en el país, especialmente en la red de educación federal que se ocupa de la educación profesional y tecnológica. Aún así, este momento ha llevado a avances reflexivos que fomentan la necesidad inmediata de promover condiciones para que 
esta modalidad pueda llegar a estar en el país para superar los desafíos post-pandemia de COVID-19.

Palabras clave: Educación a distancia; Pandemia; Educación profesional y tecnológica.

\section{Introdução}

Atualmente, o mundo está acometido por uma epidemia dramática nomeada de Coronavírus $^{1}$, que tem alterado forçadamente o comportamento e exigido o distanciamento social. Nesse caso, as instituições escolares também tiveram que adaptar a sua rotina, bem como as suas práticas educativas.

Em conformidade com a Organização das Nações Unidas para a Educação, a Ciência e a Cultura (Unesco, 2020), mais de 150 países implementaram o fechamento em todo o país dos espaços escolares, provocando impacto em torno de $80 \%$ da população estudantil do mundo. Ainda, há países que realizaram a interrupção na educação de modo localizado. Para tanto, a Unesco (2020) recomenda 10 (dez) elementos que podem vir a garantir a aprendizagem durante a vigência deste período: examinar a disponibilidade e a escolha das ferramentas mais relevantes; garantir a inclusão dos programas de Educação a Distância $(\mathrm{EaD})$; proteger a privacidade e a segurança dos dados; priorizar soluções para enfrentar os desafios psicossociais antes de ensinar; planejar o cronograma de estudos dos programas de ensino a distância; fornecer o apoio a professores e aos pais no uso de ferramentas digitais; combinar abordagens adequadas e limite a quantidade de aplicativos e plataformas; desenvolver regras de $\mathrm{EaD}$ e acompanhar o processo de aprendizagem dos estudantes; definir a duração das unidades nesta modalidade educacional com base nas habilidades de autorregulação dos estudantes; criar comunidades e aumentar a conexão.

No Brasil, a Portaria no 343, de 17 de março de 2020, dispõe sobre a substituição das aulas presenciais por aulas em meios digitais, enquanto durar a situação de pandemia de Coronavírus (COVID - 19) (Brasil, 2020a). Conforme o Art. 1 da referida portaria, autorizase a substituição das unidades curriculares presenciais em andamento, em caráter excepcional, pelo período de até trinta dias, podendo ser prorrogável,

\footnotetext{
${ }^{1}$ O COVID-19 caracteriza-se como uma doença causada pelo novo coronavírus, que foi nomeado de Sars-CoV2.
} 
[...], por aulas que utilizem meios e tecnologias de informação e comunicação, nos limites estabelecidos pela legislação em vigor, por instituição de educação superior integrante do sistema federal de ensino, de que trata o art. $2^{\circ}$ do Decreto $\mathrm{n}^{\circ} 9.235$, de 15 de dezembro de 2017 (Brasil, 2020a).

Ainda, a Medida Provisória No 934, de $1^{\circ}$ de abril de 2020 (Brasil, 2020b), estabelece normas excepcionais sobre o ano letivo da educação básica e do ensino superior decorrentes das medidas para o enfrentamento da situação de emergência de saúde pública de que trata a Lei $\mathrm{n}^{\circ}$ 13.979, de 6 de fevereiro de 2020. O Conselho Nacional de Educação (CNE) (Brasil, 2020c) aprovou as diretrizes para orientar escolas da educação básica e instituições de ensino superior durante a pandemia de Coronavírus. Diante desta realidade, inúmeras instituições escolares aderiram à $\mathrm{EaD}$ e, alguns estudos acerca do momento atual e suas implicações na educação, já podem ser vislumbrados (Camacho, Joaquim, Menezes, \& Sant’Anna, 2020, Castaman, \& Rodrigues, 2020, Churkin, 2020, Oliveira, \& Souza, 2020, Tostes, \& Melo Filho, 2020).

Conceituar esta modalidade educacional a distância não é uma tarefa simples, uma vez que em virtude das transformações do mundo da vida e dos avanços da tecnologia, esta caracterização também é ressignificada constantemente. Nunes (1994, p. 09) ressalta que

Educação a distância pressupõe um processo educativo sistemática e organizado que exige não somente a dupla via de comunicação, como também a instauração de um processo continuado, onde os meios ou os multimeios devem estar presentes na estratégia de comunicação.

A EaD é uma modalidade de ensino que faculta ao estudante estar fisicamente presente no mesmo local em que o professor (Mesquita, Piva Jr., \& Gara, 2014). Considerando essa realidade, este estudo encontra-se delimitado com a seguinte problematização: em tempos de pandemia, como está sendo mediado o ensino a distância na Educação Profissional e Tecnológica (EPT)? Para tentar responder este questionamento almeja-se conhecer as definições e os fundamentos da $\mathrm{EaD}$, com a finalidade de examinar o embasamento legal e a adoção do ensino a distância no Instituto Federal de Educação, Ciência e Tecnologia do Amazonas (IFAM) - Campus Parintins.

Assim, este artigo de abordagem qualitativa, do tipo bibliográfica está dividido em 03 (três) partes: a) apresenta os procedimentos metodológicos; b) discute os conceitos e os documentos regulatórios da $\mathrm{EaD}$ no Brasil; c) trata da legislação e da adoção do ensino a distância no IFAM - Campus Parintins 


\section{Metodologia}

Diante de seu propósito, este estudo básico caracteriza-se como uma investigação de objetivo exploratória como preconiza Pereira et al. (2018), ancorada em uma abordagem qualitativa e dialética, seguindo os movimentos e as contradições ontológicas dos espaços educativos. Para Minayo (2007), a pesquisa qualitativa trabalha com o universo de significados, motivos, aspirações, crenças, valores e atitudes, o que correlaciona a relações, processos e fenômenos que não podem ser reduzidos à operacionalização de variáveis.

A pesquisa exploratória tem como finalidade proporcionar maior familiaridade com o problema, com o intuito de torná-lo mais explícito ou a construir hipóteses. A maioria desses estudos envolve: (a) levantamento bibliográfico; (b) entrevistas com pessoas que tiveram experiências práticas com o problema pesquisado; e (c) análise de exemplos que estimulem a compreensão (Gil, 2007; Pereira et al.,2018). Ademais, considera-se também como uma pesquisa descritiva, a partir do processo analítico exploratório. Dito isso, a descrição dar-se-á das características de determinada população ou fenômeno, ou o estabelecimento de relações entre variáveis (Gil, 2007).

Como técnica, pauta-se em uma pesquisa bibliográfica, realizada a partir de material já elaborado, composto, principalmente, de livros e de artigos científicos, esclarece Gil (2008). Para tanto, orienta-se em Nunes (1994), Azevedo (2000), Maia e Mattar (2007), Alves (2007, 2009), Abed (2008), Moran, Masetto e Behrens (2008), Lombardi, Aragão, Santos e Crestana (2010), Santos (2010), Vieira, Souza, Behr e Momo (2016), Assumpção (2019), Castaman e Rodrigues (2020), Pacheco (2020) e alguns documentos oficiais como Brasil (1996, 2004, 2005, 2008, 2012, 2015, 2016, 2017, 2018, 2019, 2020c, 2020f), para refletir sobre as definições e os fundamentos da $\mathrm{EaD}$.

Para abordar acerca da legislação e da adoção do ensino a distância no IFAM, em especial, no Campus Parintins, apoia-se nos estudos dos regulamentos: Brasil (2020e) e IFAM (2020a, 2020b, 2020c, 2020d, 2020e, 2020f, 2020g).

\section{Educação a Distância: definições e fundamentos}

O emprego da EaD no Brasil está em franco processo de expansão e de ascensão, seja nas instituições públicas ou privadas. Inúmeros autores investigaram e tentaram descrever os marcos históricos dessa modalidade educacional no Brasil (Nunes, 1994; Maia \& Mattar, 
2007; Alves, 2007, 2009; Santos, 2010), bem como circunstanciar os conceitos acerca do tema. Contudo, trata-se de uma definição abrangente.

Nunes (1994) sintetiza as concepções dos autores clássicos: Dohmem, em 1967, afirma que a $\mathrm{EaD}$ constitui-se como um modo sistemático e organizado de autoestudo, no qual o estudante instrui-se pelo material que lhe é ofertado. Nesse caso, o papel do professor é acompanhar e supervisionar o sucesso do aluno, por meio de meios de comunicação. Peters, em 1973, enfatiza que a educação/ensino a distância é um método racional de mediar conhecimentos, habilidades e atitudes, a um grande número de estudantes pela reprodução de materiais técnicos de alta qualidade. Moore, em 1973, ressalta que a comunicação do professor com o estudante deve ser facilitada por meios impressos, eletrônicos, mecânicos ou outros. Holmberg, em 1977, destaca que na Educação a Distância inclui-se várias formas de estudo, não tendo a presente do tutor no mesmo local. Keegan, em 1991, define a EaD como a separação física entre professor e estudante, a comunicação de mão dupla, com encontros ocasionais para socialização. Chaves, em 1999, caracteriza modalidade da educação a distância por meio da separação física e o uso de tecnologias de telecomunicação.

Moran, Masetto \& Behrens (2008) aludem que a EaD tem como atributo principal o emprego de tecnologias como mediação, o que permite o processo de ensino-aprendizagem, pela interação entre professores, tutores e estudantes em tempos e espaços diferentes. A Associação Brasileira de Educação a Distância (Abed, 2008) sublinha que a EaD “[...] é a modalidade de educação em que as atividades de ensino-aprendizagem são desenvolvidas majoritariamente (e em bom número de casos exclusivamente) sem que alunos e professores estejam presentes no mesmo lugar à mesma hora".

Educação a distância é a modalidade educacional na qual alunos e professores estão separados, física ou temporalmente e, por isso, faz-se necessária a utilização de meios e tecnologias de informação e comunicação. Essa modalidade é regulada por uma legislação específica e pode ser implantada na educação básica (educação de jovens e adultos, educação profissional técnica de nível médio) e na educação superior (Brasil, 2020d).

Verifica-se nestas definições e fundamentos que há elementos centrais que coadunam entre os autores, em especial, a separação física e o uso de tecnologias. Assim, uma das facilidades dessa modalidade é o acompanhamento do conteúdo a qualquer horário, sem o compromisso fixo de estar presente em uma sala de aula (Vieira et al., 2016). Neste contexto, 
a EaD permite ao estudante maior autonomia e proatividade, para que, inclusive, elabore seu perfil de aprendizagem, sua rotina e seu ritmo de estudo (Lombardi et al., 2010)

No Brasil, o ensino a distância teve sua regulamentação a partir do Art. 80, da Lei de Diretrizes e Bases da Educação Nacional (LDB) (Brasil, 1996), sendo que o seu conceito foi definido pelo Decreto $\mathrm{n}^{\mathrm{o}}$ 5.622, de 19 de dezembro de 2005 (Brasil, 2005), o qual foi revogado pelo Decreto ${ }^{\circ}$ 9.057, de 25 de maio de 2017 (Brasil, 2017).

Diante deste escopo, a Portaria $n^{\circ} 4.059$ (Brasil, 2004), que remete a Educação Superior, prevê em seu art. $1^{\circ}$ que se introduza, na organização curricular e pedagógica de cursos superiores reconhecidos, a oferta até $20 \%$ de unidades curriculares integrais ou parciais, na modalidade semipresencial. A Portaria $n^{\circ} 1.428$ (Brasil, 2018) indica sobre o oferecimento, por Instituições de Educação Superior (IES), de unidades curriculares na modalidade a distância em cursos de graduação presencial. A Portaria no 2.117 (Brasil, 2019) dispõe acerca da oferta de até o limite de $40 \%$ da carga horária total do curso de graduação presencial na modalidade EaD, por IES pertencentes ao Sistema Federal de Ensino.

Já a Resolução nº 6 (Brasil, 2012) que inscreve as Diretrizes Curriculares Nacionais para a Educação Profissional Técnica de Nível Médio, recomenda no Art. 26, a possibilidade de inserção de até $20 \%$ de carga horária diária do curso, de atividades não presenciais, desde que seja calculado na carga horária mínima prevista e estabelecida no Catálogo Nacional dos Cursos Técnicos de Nível Médio (Brasil, 2016) e que tenha suporte tecnológico e garantia de atendimento por docentes e tutores.

Destaca-se nos regulamentos brasileiros que as avaliações e os estágios (Brasil, 2008) devem ser realizados presencialmente. De acordo com o último Censo de estudantes na modalidade a distância disponibilizados pela Abed (2018), verifica-se nos Gráficos 1, 2 e 3, os número de matrículas e de oferta da $\mathrm{EaD}$ no ensino superior e técnico.

Gráfico 1 - Quantidade de cursos oferecidos em EaD no Brasil no período de 2017 e 2018.

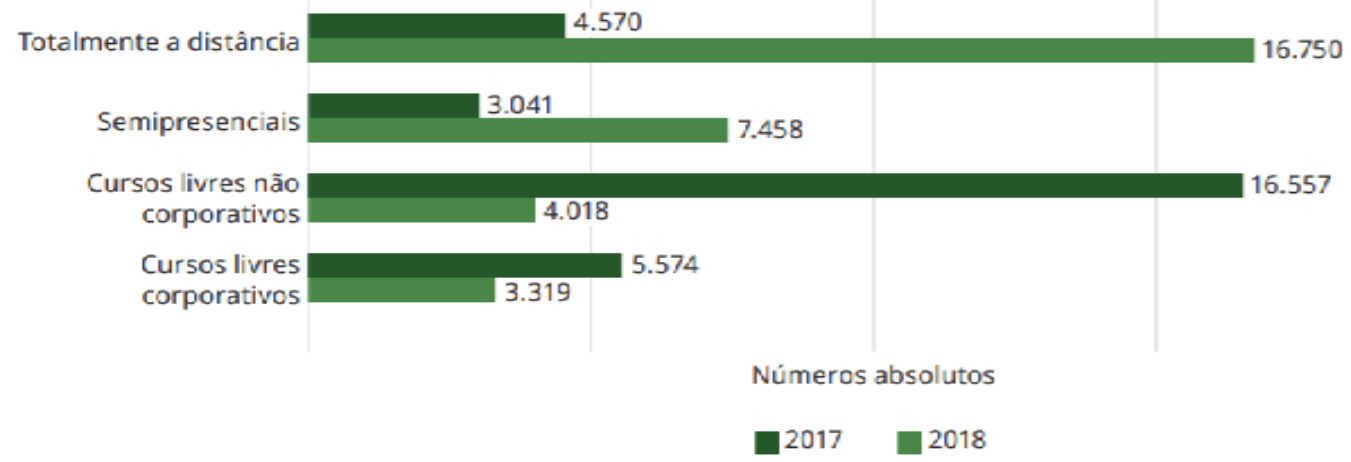

Fonte: Abed, 2018. 
Research, Society and Development, v. 9, n. 7, e491974399, 2020

(CC BY 4.0) | ISSN 2525-3409 | DOI: http://dx.doi.org/10.33448/rsd-v9i7.4399

Gráfico 2 - Oferta de cursos regulamentados totalmente a distância, categorizados por nível, desde 2016, por nível acadêmico.

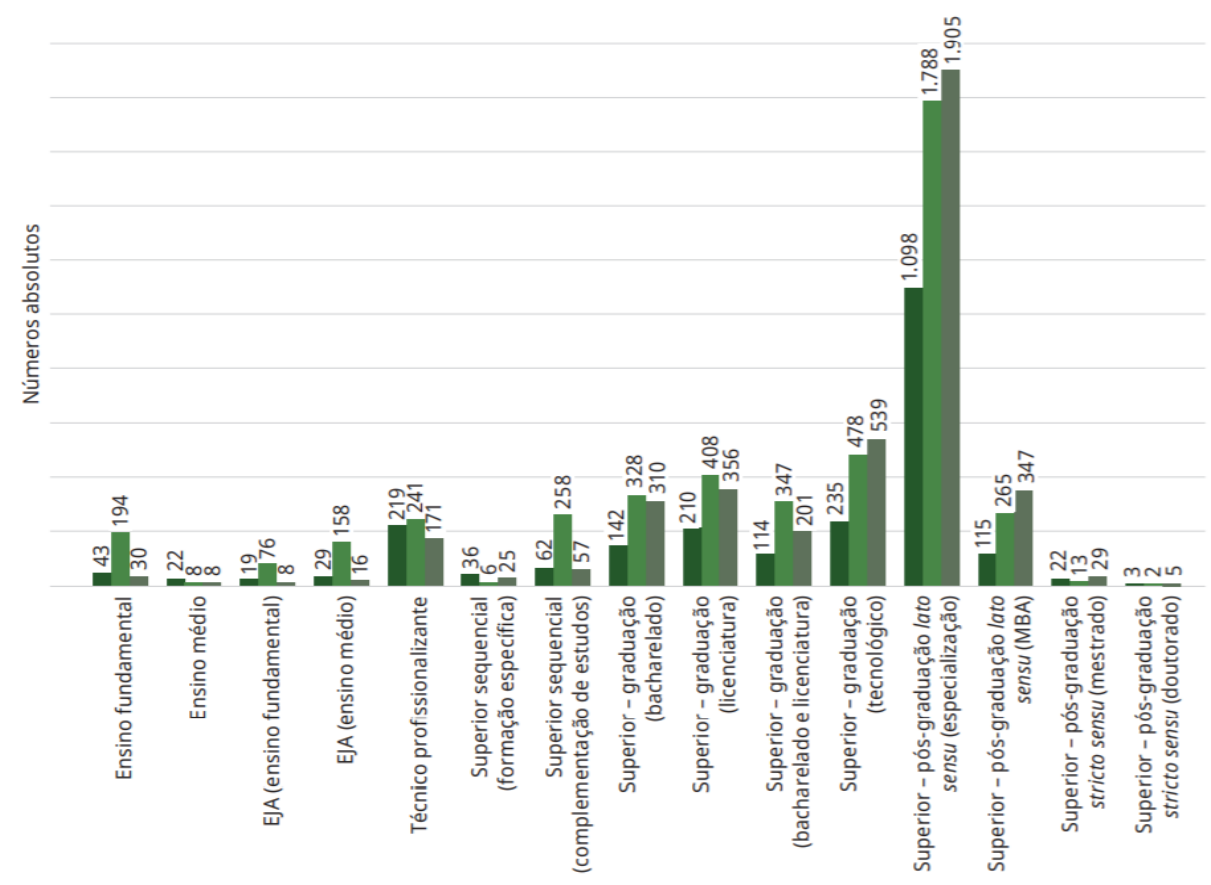

Fonte: Abed, 2018.

Gráfico 3 - Evolução do total de matrículas em cursos regulamentados totalmente a distância desde 2009

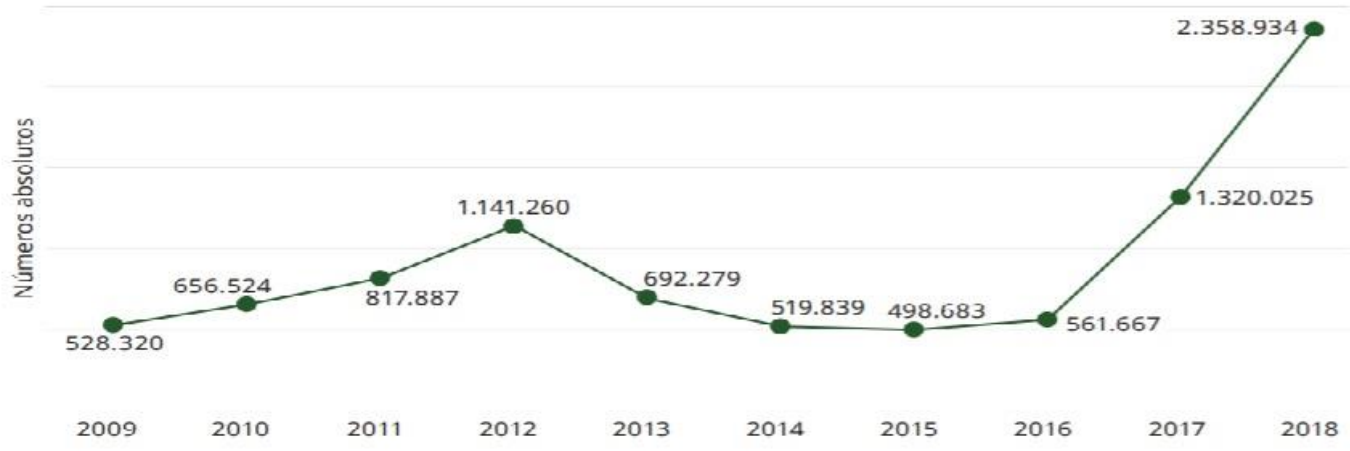

Fonte: Abed, 2018.

No Plano Nacional de Educação (Brasil, 2015), a Meta 11 reforça a expansão nas matrículas da EPT de nível médio na rede federal da EPT, assim como fomenta a expansão da oferta dessa modalidade nas redes públicas estaduais de ensino e também de EaD. Além disso, a Estratégia 14.4, indica a ampliação do emprego de metodologias, de recursos e de tecnologias de EaD. 
Conforme dados levantados pelo Censo EaD BR 2018 (Assumpção, 2019), o recurso mais utilizado atualmente na EAD são as teleaulas, tanto em cursos totalmente a distância $(92,6 \%)$, quanto em semipresenciais $(81,8 \%)$. O segundo mecanismo citado são os textos digitais (artigos, apostilas, capítulos de livros etc.), com 83,7\% em cursos totalmente a distância e 78,2\% em cursos semipresenciais. Outros recursos apontados foram: livros eletrônicos (e-books), vídeos de diferentes gêneros que não sejam teleaulas, objetos digitais de aprendizagem, inteligência artificial, a realidade virtual e aumentada (chamada de realidade mista), a blockchain e os assistentes virtuais, etc. Averígua-se um aumento de 7\% de 2017 para 2018, dado este que pode ser em virtude da evolução de aparatos relacionados à acessibilidade; o emprego da tecnologia necessária para a criação desses recursos; a intensificação do uso de estratégias como aulas invertidas e outras metodologias ativas; e a tendência à humanização do ambiente on-line.

A Educação a Distância tenta garantir sua qualidade, especialmente, pelos recursos de Tecnologia da Informação e Comunicação (TIC):

[...] há a percepção clara de que estamos diante de uma tecnologia que permite coisas impensáveis em outras modalidades que utilizam outras tecnologias, como, por exemplo, a formação de comunidades virtuais de aprendizagem colaborativa, isto é, comunidades compostas por pessoas que estão em diversas partes do mundo e que interagem todas com todas sem que necessariamente estejam juntas ou conectadas na mesma hora e no mesmo lugar - em modo assíncrono, como dizem os especialistas (Azevedo, 2000, p. 01-02).

Os Institutos Federais de Educação, Ciência e Tecnologia (IF), enquanto instituições de ensino, fundadas na politecnia (Pacheco, 2020), desde sua implantação, compuseram um grupo de políticas de oferta da EaD para a EPT, as quais consolidam os princípios e a proposta político-pedagógica dos IF. Mas, o IF ainda possui a primazia no ensino presencial (Castaman, \& Rodrigues, 2020) e são paulatinas as experiências em EaD na EPT.

Destarte, a Pandemia e, o contexto conjuntural por ela instaurados obrigou os IF a se reinventarem. De acordo com dados ${ }^{2}$ viabilizados em Portal de monitoramento das instituições de ensino diante do Coronavírus (Brasil, 2020f), dos 41 IF, 32 estão com atividades administrativas e acadêmicas suspensas, sendo 763.205 estudantes sem aulas. Assim, foram poucos IF no Brasil que adotaram a modalidade EaD durante este período de imediatismo e de imprevisibilidade imposto pelo COVID-19. Para tanto, a seguir, reflete-se

\footnotetext{
${ }^{2}$ Dados coletados no dia 09 de maio de 2020.
} 
sobre o IFAM - Campus Parintins que considerou inicialmente a EaD e a assumiu para facilitar o processo de ensino-aprendizagem e minimizar os impasses advindos da pandemia.

\section{A Legislação e a Adoção do Ensino a Distância no IFAM - Campus Parintins}

Na segunda semana de março de 2020, o IFAM - Campus Parintins começou a receber as instruções normativas devido ao COVID-19. Na instrução Normativa $n^{\circ} 19$ (Brasil, 2020e) estabeleceu-se as orientações aos órgãos e as entidades do Sistema de Pessoal Civil da Administração Pública Federal (SIPEC), quanto às medidas de proteção para o enfrentamento da emergência de saúde pública de importância internacional decorrente da pandemia. Tal instrução versou sobre os cuidados e a atenção de prevenção, bem como acerca dos afastamentos de servidores por contágio.

A Ordem de Serviço Conjunta nº 01 (Ifam, 2020a) das Pró-reitorias de Ensino (PROEN), Pesquisa (PPGI) e Extensão (PROEX), orientou os procedimentos acerca da interrupção das atividades acadêmicas presenciais no período de 18 de março a 01 de abril do corrente ano, e estabeleceu sua substituição por atividades remotas, garantindo o suporte tecnológico e pedagógico para a realização de tal, no âmbito do IFAM, com vistas a prevenção do contágio e ao enfrentamento da emergência de saúde pública, originada pelo Coronavírus.

Por conseguinte, a portaria $n^{\circ} 472$ (Ifam, 2020b), suspendeu as atividades presenciais até 01 de abril de 2020 e estabeleceu que as atividades administrativas essenciais e as estratégicas teriam ato normativo específico pela PROEN, PROEX e PPGI. Suspendeu viagens e quaisquer evento com aglomeração de pessoas. Além disso, recomendou que qualquer servidor ou docente que retornasse de viagens internacionais ficaria em observação por, no mínimo, sete dias e que qualquer servidor ou estudante que manifestasse sintomas de COVID-19 comunicasse imediatamente a gestão de pessoas e ficasse em observação por quatorze dias. A portaria também determinou que as atividades de $\mathrm{EaD}$ ficariam mantidas no período.

A Portaria Conjunta $n^{\circ} 01$ (Ifam, 2020c) e outros regulamentos ${ }^{3}$, dispostos no mês de março de 2020, nortearam o ensino remoto, que permitiram a substituição das aulas presenciais pela $\mathrm{EaD}$, garantindo o suporte tecnológico - digital ou não - e pedagógicos apropriados. Estabeleceram o prazo de cinco dias para que os docentes publicassem materiais

\footnotetext{
${ }^{3}$ Mediante a lei no 9394/96, a Resolução Conselho Nacional de Educação CNE/CEB nº 06, de 20 de setembro de 2012, a Portaria MEC n 2117, de 06 de setembro de 2019, a Resolução CNE/CES nº 01, de 06 de abril de 2018, a Portaria CAPES n 90 , de 24 de abril de 2019 e demais atos normativos, infralegais do CNE e do Ministério da Educação (MEC).
} 
para atividades a distância a serem executadas pelos alunos, cujos conteúdos seriam acompanhados pelos coordenadores de curso e pela coordenação pedagógica da instituição, bem como resolveu que algumas atividades administrativas seriam presenciais e outras remotas e deliberou a suspensão de atividades no ginásio poliesportivo. Neste sentido, a Coordenação Geral de Ensino informou aos coordenadores de curso Integrado, Subsequente, Superior e Proeja que os mesmos orientassem os professores, dos respectivos cursos, para obrigatoriamente publicarem as aulas pelo Sistema Integrado de Gestão Acadêmica (SIGAA) e o conteúdo poderia também ser mediado por outras redes sociais. Porém, era indispensável o acesso dos educandos no SIGAA, devido ao registro das aulas estar mantido no sistema, bem como seria a comprovação de que o docente efetivamente realizou sua atividade em EaD. Assim ficou determinado, que:

O desenvolvimento das aulas e demais atividades de ensino, pesquisa e extensão dos cursos regulares serão realizadas à distância, por meio do módulo SIGAA do Sistema Integrado de Gestão (SIG), como ferramenta EAD, e com direcionamento para estudos dirigidos (Ifam, 2020C).

Aos educandos que tivessem restrições de acesso sugeriu-se a oferta de estudos dirigidos, ação essa suspensa no decorrer do período por orientação jurídica devido às possibilidades de contágio na entrega de materiais entre servidores e estudantes. As atividades de ensino foram efetivadas por meio de um ícone disponível no Ambiente Virtual de Aprendizagem (AVA), denominado "Turma Virtual”. Desta forma, define-se como atividades a distância:

I - o estudo dirigido (e sua variável de recuperação da aprendizagem, a tarefa dirigida) é uma técnica de ensino que tem por objetivo guiar e estimular o aluno para o estudo individual e para o pensamento reflexivo. Neste tipo de metodologia, o trabalho é apresentado na forma de problemas, cujas soluções o aluno deverá buscar por esforço próprio com autonomia e responsabilidade.

II - atividades realizadas em ambientes virtuais, tais como: vídeos aulas gravadas, atividades formativas, fóruns, questionários, leituras, entre outras.

III - atendimento online mediado pelo docente e transmissão simultânea, a exemplo das webconferências, chat (salas de bate papo), entre outras (Ifam, 2020c).

Coube, deste modo, à Gestão do Campus juntamente com suas unidades técnicas e gestoras do ensino apresentar relatório das atividades acadêmicas realizadas neste período, contendo as ações e as ferramentas (meios) utilizadas para compensação dos dias suspensos, bem como apoiar, monitorar e orientar para que cada docente realizasse as devidas alterações 
em seus planos de ensino, de forma a demonstrar as reprogramações em detrimento de COVID-19.

Na sequência, a Portaria $n^{\circ} 20$ (Ifam, 2020d) levando em consideração alguns regulamentos norteadores, instituiu a modalidade $\mathrm{EaD}$ como método para a composição das atividades de ensino, no período de 02 a 23 de abril de 2020, nos campi enquadrados no Art. $1^{\text {o }}$ da Portaria $n^{\circ} 19$ (Ifam, 2020g). Destarte, conforme Portaria n ${ }^{\circ} 20$, Art. $1^{\text {o }}$ e seus incisos,

$\S 2^{\circ} \mathrm{O}$ registro das atividades de ensino deverá ocorrer exclusivamente no Sistema Acadêmico - SIGAA no Ambiente "Turma Virtual".

$\S 3^{\circ}$ Para o desenvolvimento das atividades de ensino os docentes poderão utilizar como ferramentas adicionais Ambientes Virtuais de Aprendizagem (AVAs), ou outras ferramentas da Tecnologia de Informação e Comunicação - TICs, tais como:

I - Moodle Institucional;

II - Google Sala de Aula (ClassRoom);

III - WhatsApp;

IV- Telegram;

V - Google Meet;

VI - Google Formulário;

VII - Youtube;

VIII - Email.

IX - Skype;

$\mathrm{X}$ - Aplicativos educativos;

XI - Bibliotecas virtuais gratuitas;

XII - Formas de estudos convencionais - Estudo dirigido (uso dos livros didáticos, apostilas, slides impressos, leitura de literaturas, lista de exercícios de conteúdos já estudados, roteiros de estudos com explicações claras da resolução das tarefas, e

XIII- Outras ferramentas didático-pedagógicas, mediante autorização prévia da Diretoria de Ensino/Chefia de Departamento de Ensino (Ifam, 2020d).

Outrossim ficaram suspensas as atividades de práticas profissionais de estágios e de laboratório, e para o cumprimento de tal Portaria, estavam diretamente envolvidos: a PróReitoria de Ensino; a Diretoria de Ensino/Chefia de Departamento de Ensino dos campi; a Coordenação de Ensino, Curso e/ou equivalentes dos campi; a Coordenação/Setor TécnicoPedagógico/Equipe Multiprofissional e/ou equivalente dos campi; o Corpo Docente; o Corpo Discente; e a(o) Representante de Turma. A Pró-Reitoria de Ensino ficou incumbida de organizar os procedimentos para permitir a continuidade das atividades de ensino no IFAM e de avaliá-las periodicamente (Ifam, 2020d).

À Diretoria de Ensino/Chefia de Departamento de Ensino dos campi coube anunciar às comunidades interna e externa as medidas praticadas; zelar pelo cumprimento das ações de ensino; publicar as portarias internas sobre as medidas de excepcionalidade em razão de COVID-19 e; constituir dispositivos de atendimento às comunidades interna e externa para 
esclarecimento de dúvidas (Ifam, 2020d). À Coordenação de Ensino, Curso e/ou equivalente dos campi responsabilizou-se por fiscalizar a atualização dos Planos de Ensino no SIGAA; acompanhar as atividades de ensino relativas aos períodos da excepcionalidade; monitorar o acesso dos estudantes nas turmas virtuais do SIGAA e demais ferramentas de interação e de comunicação digital e; acompanhar os estudantes que não têm acesso à nenhum recurso da TDIC (Ifam, 2020d).

Tangeu à Coordenação/Setor Técnico-Pedagógico/Equipe Multiprofissional dos campi conduzir a atualização dos Planos de Ensino no SIGAA; orientar os docentes sobre as alterações didático-metodológicas das atividades de ensino, além de dar assistência acadêmica, intermediando quando necessário, a relação aluno-professor; orientar o planejamento integrado, de forma a viabilizar a interdisciplinaridade entre as aulas, com a finalidade de minimizar o número expressivo de atividades/tarefas demandadas aos estudantes; amparar os docentes na elaboração de ações que avaliem de modo integral o aluno; dialogar com os estudantes sem acesso às TDIC, para possibilitar o encaminhamento dos planos de estudo dirigido, em horário a ser definido pelo campus (Ifam, 2020d).

Pela Portaria, o Corpo Docente deveria atualizar o Plano de Ensino no SIGAA referente ao período da excepcionalidade, consoante aos calendários acadêmicos, ajustando as metodologias às características da Modalidade EaD; inserir no campo "Metodologia de ensino e avaliação - Metodologia e Instrumentos a serem usados pelo docente", na aba do Plano de Ensino no SIGAA, as informações quanto ao AVA utilizado na respectiva unidade curricular e os relatórios gerados pelo mesmo para comprovar os acessos dos estudantes a mesma (Ifam, 2020d).

Ademais, os docentes tiveram a obrigatoriedade de fazer uso de todos os recursos, as atividades e as avaliações realizadas, sendo estas inseridas na "Turma Virtual" do SIGAA, na aba "Materiais e Atividades". Ainda, foi indispensável viabilizar o acesso à Coordenação de Ensino, Curso e/ou equivalente, na totalidade das turmas, independente do AVA para que atue como "colaborador"; manter o preenchimento dos Diários de Classe; acompanhar, orientar e comprovar a participação dos estudantes, atendendo a participação e a realização das atividades avaliativas propostas nas inúmeras plataformas digitais e/ou por estudo dirigido, declarando no SIGAA (Ifam, 2020d).

Também ao docente incumbiu-se a atualização do Plano de Ensino, haja vista as possibilidades de atividades didático-pedagógicas, dada a excepcionalidade, inserindo: leituras de artigos, livros, textos, etc; resolução de questões e problemas quantitativos e qualitativos; relatórios, análises, sínteses, resumos; interpretação de textos, problemas, vídeos, 
estudos de caso etc, debates virtuais ou textuais; participação em fóruns, chats, wikis; postagens de vídeos e comentários com base no conteúdo abordado; e outras atividades, bem como assegurar a disponibilidade virtual, durante os horários das aulas presenciais para o atendimento aos discentes e estimular a interação entre estudantes, a partir de recursos como fóruns de discussões, debates, desafios acerca de assuntos atrelados às unidades curriculares, etc. Contudo, para as unidades curriculares ministradas diretamente na "Turma Virtual" do SIGAA, não houve a necessidade de comprovações adicionais por parte do docente (Ifam, 2020d).

Ao Corpo Discente coube acompanhar a atualização dos Planos de Ensino mediante acesso ao SIGAA; realizar login no AVA pelas credenciais institucionais; acompanhar, executar, (des)envolver atividades projetadas em cada unidade curricular, em consonância com a metodologia definida pelo docente; comunicar/registrar às coordenações de curso, equipe pedagógica e chefia de departamento de ensino, eventualidade(s) ocorrida(s) neste período, que impeça o acesso às atividades propostas pelo docente, via e-mail a ser disponibilizado pelos campi, para fins de atendimento orientado, ao término deste período de isolamento social; manter a comunicação com os docentes nos horários das aulas presenciais, por intermédio dos aparatos disponíveis, para esclarecer dúvidas (Ifam, 2020d).

Segundo a Portaria (Ifam, 2020d), tocou ao Representante de Turma incentivar a turma; acompanhar as atividades mediadas pelos docentes nos AVA; discorrer ao término da etapa as adversidades apresentadas pela turma; intermediar os impasses apresentadas pela turma na interação estudante/professor; manter comunicação com os Coordenadores de Curso. No Art. 10, cita-se acerca da excepcionalidade do não acesso à internet ou aos aplicativos e plataformas digitais, prescrevendo a adoção da estratégia de estudo dirigido.

$\S 1^{\circ}$ Para complementação do estudo dirigido poderão ser utilizadas outras estratégias como impressão de materiais, portfólios e apostilas;

$\S 2^{\circ}$ Para a comunicação/interação poderão ser utilizados: telefone, mensagens de áudio/vídeo, WhatsApp, rádio local, dentre outros meios;

$\S 3^{\circ}$ Os discentes que não possuem acesso algum às TICs, recomenda-se efetivar comunicação com a Coordenação de Ensino, Curso e/ou equivalente para as providências necessárias [...] (Ifam, 2020d).

Quanto à avaliação no período das atividades a distância, a Portaria trata que para fins de controle e de avaliação dos estudantes deve-se encaminhar as atividades realizadas escaneadas (via celular) ou por meio de fotos (via WhatsApp), identificadas com o nome do estudante, conforme a metodologia e o prazo estabelecido pelo docente. Aos estudantes sem 
acesso algum às informações, o campus adotou a estratégia de impressão do material e de disponibilização no campus, aderindo aos cuidados necessários à preservação da saúde e da distância de 2 (dois) metros entre as pessoas, convergente às orientações do Ministério da Saúde e da Organização Mundial de Saúde (Ifam, 2020d).

Considerando a singularidade do momento, para a conclusão da primeira etapa dos Cursos Técnicos de Nível Médio realizou-se pelo menos uma avaliação com o intuito de validação da etapa e do registro no SIGAA, aproveitando o acesso à "Turma Virtual" dos estudantes e a outras plataformas digitais. No entanto, os estudantes, sem acesso a "Turma Virtual" e que estavam sendo atendidos, exclusivamente, pelas estratégias de estudo dirigido com material impresso ou em mídia, a avaliação foi realizada pela solicitação de trabalho (Ifam, 2020d).

Quanto ao procedimento de recuperação paralela, tendo em vista a suspensão das aulas presenciais, efetuou-se o planejamento e a realização reprogramada para o retorno das atividades regulares. Mas, nos casos em que houve a impossibilidade do campus assumir as estratégias elencadas, o docente deverá elaborar um plano de reposição para os estudantes não atendidos por aula remota (Ifam, 2020d).

A legislação que regulamentou as atividades a distância aqui debatidas serviram de mola propulsora para a realização de experiência docente e discente em tempos de pandemia. Desta forma, os docentes foram conduzidos e, até mesmo, "obrigados" a acessar o SIGAA não apenas para as atualizações das turmas presenciais, mas para o atendimento do processo de trabalho com as "turmas virtuais", inserindo materiais como arquivos, conteúdos/páginas da $w e b$, referências e vídeos. Ainda, houve a necessidade de elaborar questionários e blocos de questões, bem como analisar as estatísticas de acesso dos alunos, ações realizadas e notas, tendo uma visão de toda a movimentação dos mesmos no ambiente virtual.

Além da aprendizagem de domínio didático-pedagógico, o momento e a legislação aproximaram por meio das ações nas "turmas virtuais" docentes e discentes, da mesma maneira em que houve a troca de informações e de ações metodológicas entre os docentes com a finalidade do compartilhamento das boas práticas e de rever ações e iniciativas que não primavam pela educação pública, gratuita, de qualidade e inclusiva. Diante do exposto, discorre-se acerca da resistência, dos desafios e dos avanços da $\mathrm{EaD}$, em meio a pandemia no IFAM - Campus Parintins, a partir do relato de experiência e de alguns dados estatísticos elaborados pelas Coordenações de Curso e Direção de Ensino, disponibilizados publicamente via Whatsapp para análise. 


\subsection{Resistência}

Toda a legislação discorrida ao longo deste texto regulamentou os processos didáticopedagógicos e a transição do ensino totalmente presencial para um ensino $100 \%$ online no período da pandemia de COVID-19. Essa doença trouxe um grande desafio aos educadores de todo o Brasil, em especial, pela necessidade de mergulhar no entendimento de práticas didático-pedagógicas desconhecidas, a procura do entendimento dos processos adequados para a implantação e a operacionalização de aulas na EaD. Tal modalidade não é desconhecida do meio acadêmico e está longe de ter sua teoria e sua prática ignorada por profissionais ligados à educação. Porém, ao que tange a sua aceitação observa-se um abismo e, é este que constitui a principal resistência na aplicação do EaD nas instituições da EPT de todo o Brasil.

Todas as instituições, com aulas, em sua maioria, presenciais, sem exceções, enfrentaram e enfrentam resistência. Mesmo os profissionais que de certa forma, neste momento aceitaram a modalidade para se adequar a excepcionalidade, não o fazem de todo o querer ou até mesmo procurando avançar nos usos da TDIC que na retomada das atividades presenciais seriam de grande ajuda para superar as perdas no processo de ensinoaprendizagem que o período vai requerer.

A resistência docente é percebida sob dois aspectos fundamentais: a falta de formação de professores para o trabalho na $\mathrm{EaD}$ e a precariedade do acesso às TDIC, incluindo equipamentos adequados e ferramentas online.

$\mathrm{Na}$ formação de professores, os cursos para utilização do SIGAA "turmas virtuais" e os cursos de formação sobre $\mathrm{EaD}$ e sua aplicabilidade foram disponibilizados após início da Pandemia de COVID-19, o que se constituiu a primeira resistência com o início das dificuldades, bem como de desafios dos docentes em uma bipolaridade entre o "ter" que realizar e os entraves para efetivar com qualidade a demanda educacional do momento.

O primeiro curso disponibilizado foi "Uso do SIG e do Google como plataformas de educação a distância", no período de 23 de março de 2020 a 13 de abril de 2020, com carga horária de 22 horas e com uma porcentagem de participação que ficou em $15 \%$ dos docentes do IFAM. Desta forma, os docentes que participaram e os que buscaram entender por conta própria o domínio de tais ferramentas, começaram a conhecer as possibilidades de salas de aulas virtuais, de conexão ao meet, de postagens de textos e de atividades e de acesso a chats no ambiente virtual. Porém, percebeu-se que muitos docentes não tinham acesso à internet nas residências pela oferta deficitária e de custo elevado, impossibilitando que o mesmo ficasse 
remotamente trabalhando e retornasse ao campus para realizar as postagens e verificar os acessos dos educandos no SIGAA.

Também, os docentes pautaram que, fora a dificuldade de acesso à internet domiciliar, não possuíam recursos tecnológicos como celulares mais potentes, notebook, impressoras, scanner ou computador de mesa para elaborar um bom designer das aulas postadas. Muitos docentes improvisaram vídeos, por meio do WhatsApp para explicar os conteúdos, observando um mínimo de tempo de compartilhamento, já que no ambiente do SIGAA, "Turma Virtual”, ao postar os vídeos não se teria a edição e o acesso reduzido dos estudantes, o que levou a observação da necessidade de se ter um estúdio com equipamentos como câmeras de filmagens, lousa virtual e suporte de servidores do departamento de Tecnologia de Educação, ou exclusivos para o departamento de $\mathrm{EaD}$, para edição e veiculação dos vídeos. Uma observação relevante foi o uso de celulares e computadores pessoais para as atividades em $\mathrm{EaD}$, visto que os professores não receberam da Instituição e, muito menos do governo equipamentos para, exclusivamente, trabalharem na referida modalidade.

Quanto a acessibilidade ao SIGAA para realizar as tarefas, por parte dos estudantes, destaca-se que menos de $60 \%$ dos alunos dos cursos integrados, subsequentes e de graduação tiveram acesso. Já no PROEJA, o número de estudantes ficou em 26,08\%. Portanto, inviabilizou o ensino a distância a partir do SIGAA.

Observou-se também que os percentuais aumentavam para, em média, 70\% de acessos aos conteúdos nos cursos integrados, subsequentes e de graduação quando utilizado o WhatsApp.

Verifica-se com maior precisão estes dados no Gráfico 4 e $5^{4}$. Constata-se que esta situação não atendeu a legislação, como a Portaria no 19 (Ifam, 2020g) que estabelecia um número de acessos superior a $60 \%$ para viabilizar a $\mathrm{EaD}$ como prática de inclusão e de acesso de todos à educação pública e de qualidade, deixando muitos a margem do processo educacional e do acesso aos materiais e às informações postadas no AVA.

\footnotetext{
${ }^{4}$ Em relação aos gráficos 4 e 5, as siglas referem-se as informações dispobinilizadas por cada Coordenação de Curso em relação ao acesso dos estudantes matriculados nos referidos cursos: CCCPROEJA - Coordenação do Curso Profissional de Jovens e Adultos; CTAGRO - Coordenação do Curso Técnico em Agronegócio; CCTINFO - Coordenação do Curso Técnico em Informática; CCTADM - Coordenação do Curso Técnico em Administração; CCTMA - Coordenação do Curso Técnico em Meio Ambiente; CCTRP - Coordenação do Curso Técnico em Recursos Pesqueiros.
} 
Research, Society and Development, v. 9, n. 7, e491974399, 2020

(CC BY 4.0) | ISSN 2525-3409 | DOI: http://dx.doi.org/10.33448/rsd-v9i7.4399

Gráfico 4 - Acesso dos estudantes do IFAM - Campus Parintins ao SIGAA.

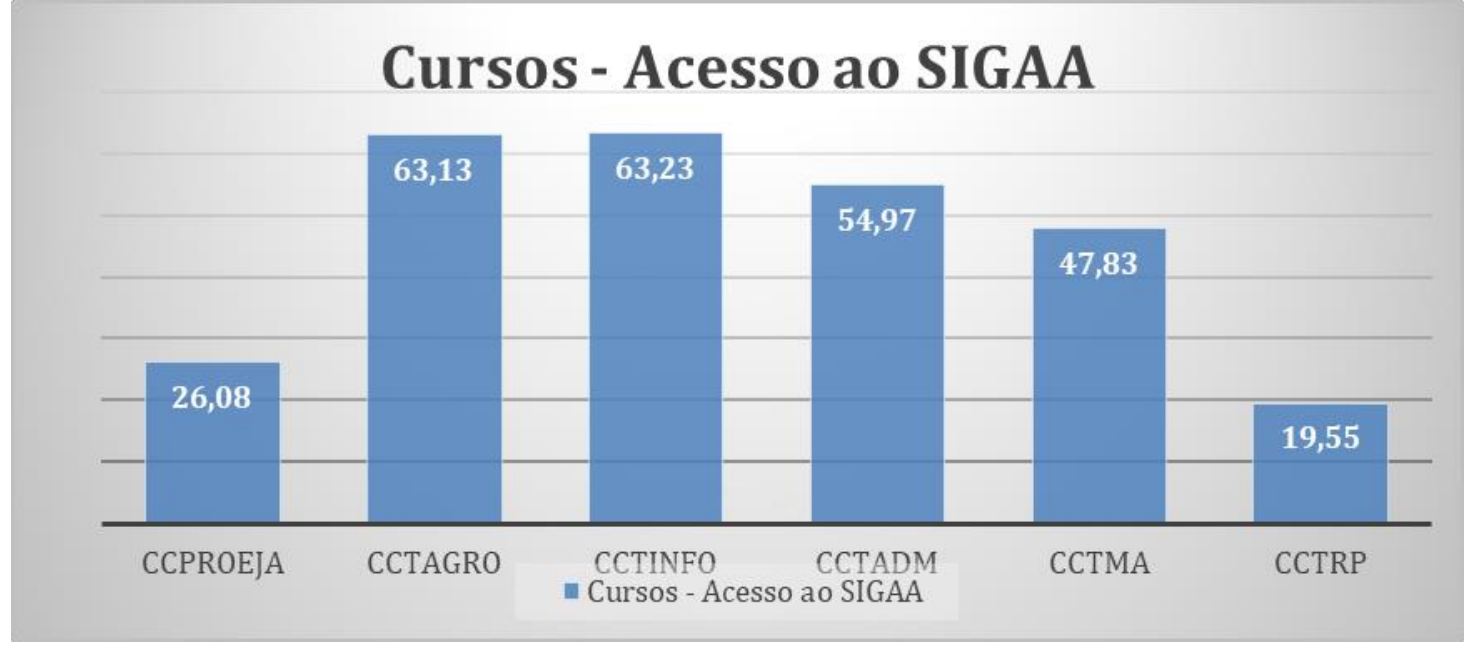

Fonte: Ifam - Campus Parintins, 2020.

Gráfico 5 - Acesso dos estudantes do IFAM - Campus Parintins ao Whatsapp.

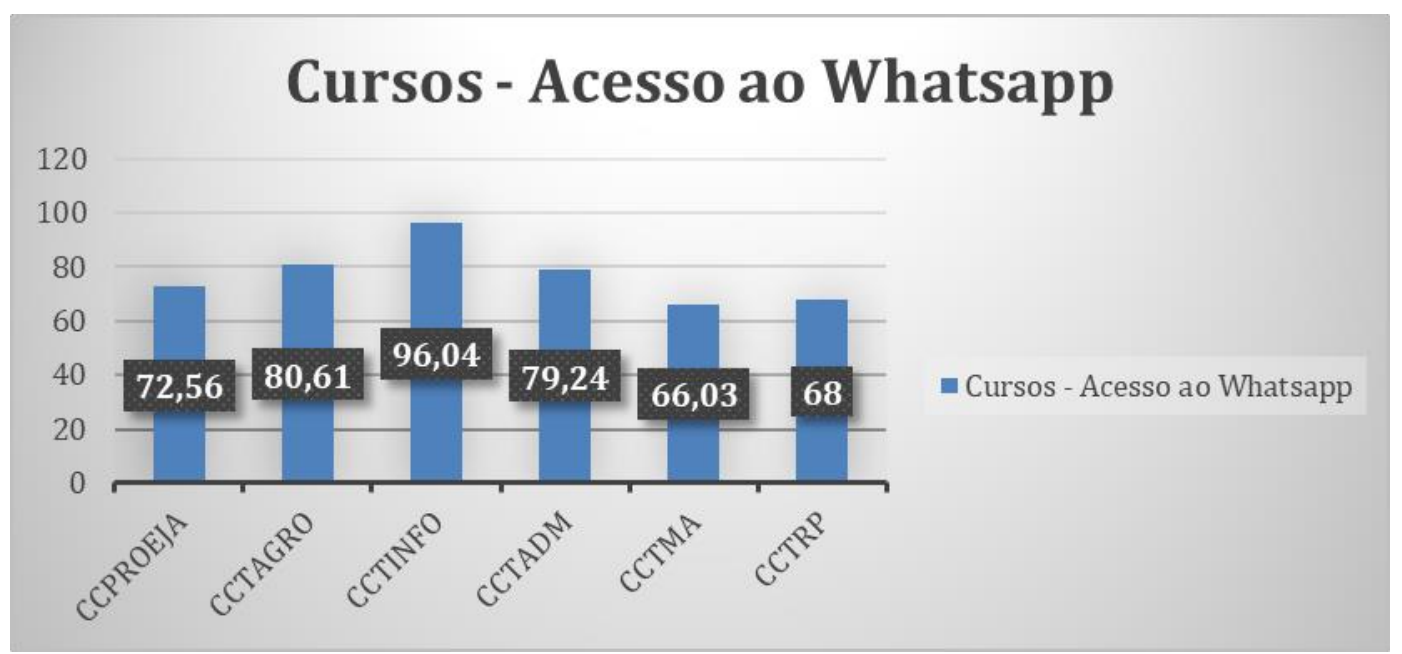

Fonte: Ifam - Campus Parintins, 2020.

O segundo complicador apresentado pelos estudantes foi a busca por lan house para realizarem as atividades, provocando aglomerações nestes locais e custos adicionais àqueles que se esforçavam para postar as atividades solicitadas. Este problema foi detectado pelos professores e pelas coordenações. Deste modo, foram realizadas orientações para que os educandos sem acesso realizassem os trabalhos e, na retomada, entregassem aos docentes responsáveis. Também, os estudantes estavam gastando valores expressivos com a compra de créditos para celulares, pois os mesmos gastavam mais para garantir o acesso ao sistema e as atividades, via SIGAA, WhatsApp e e-mail, principalmente. O terceiro problema do EaD, no IFAM - Campus Parintins enfrentados pelos educandos foram os acessos à internet do interior 
do município, visto as distâncias e as localidades remotas e sem recurso tecnológico. Assim, os estudos dirigidos poderiam apresentar uma solução com material impresso, opção que foi descartada pelo risco de contaminação na distribuição de material, tanto por alunos, como por parte dos servidores que realizariam tal tarefa de entrega e de recebimento.

\subsection{Desafios}

Diante deste contexto de pandemia, causado pelo Coronavírus e que apresenta novos desafios para a sociedade em geral e para a educação, em especial, aos ambientes educacionais em aceitar, (re)organizar e adotar com uma recepção positiva a $\mathrm{EaD}$ como meio de suprir as necessidades e as demandas educacionais atuais e vindouras. Cabe aos gestores e aos educadores promoverem e realizarem adequadamente a formação continuada para o exercício docente a distância, abarcando todas as possibilidades que as TDIC oferecem e que se atinja $100 \%$ dos educandos, pautando nesta oferta todas as unidades curriculares e as orientações, conforme a Base Nacional Comum Curricular (BNCC) e o ensino superior à contemplação do que consta no Projeto Pedagógico de cada curso e instituição de ensino superior.

Também é responsabilidade dos governos promoverem ações de acesso gratuito à internet, bem como a instrumentos tecnológicos para as redes públicas federais, aos educandos e aos educadores, a fim de que possam participar de forma construtiva de ações didático-pedagógicas que promovam a construção do conhecimento e a inclusão de todos no processo de formação integral como cidadão, por meio da EaD. Ressalta-se que esta ação poderá permitir vencer as desigualdades sociais, promover a educação de qualidade e acessível a todos e, para que os educandos tenham acesso a redes de comunicação e informação, participando ativamente da busca pelo conhecimento, por pesquisas e por cursos de extensão. Ao tornar o SIGAA e as demais ferramentas e programas - que custaram valores significativos-, realmente acessíveis e fomentadores de ensino e de debates para a melhoria da qualidade, bem como de utilidade fundamental, aproximar-se-á a educação, os educadores e os educandos dos processos de ensino-aprendizagem com eficiência.

\subsection{Avanços}

Como avanços é relevante destacar quatro aspectos. O primeiro remete a retomada da legislação sobre EaD para a discussão acadêmica, em especial, nas instituições públicas, como 
uma necessidade diante do desenvolvimento inegável do avanço das TDIC e do mundo em que o educando está inserido, possibilitando repensar os processos de ensino-aprendizagem neste contexto vivido e nos que se seguirem.

Em segundo lugar, o desafio da gestão do IFAM, em especial, o Campus Parintins em fazer um movimento em torno da capacidade da aplicação da EaD diante da Pandemia, mobilizando a comunidade escolar para que todos se envolvessem e desenvolvessem metodologias possíveis de aplicação, seja em redes sociais, seja no SIGAA, mas com mais possibilidade de acesso pelos professores e educandos. Terceiro ponto a enfatizar foi o empenho efetivo de todos os educadores na tarefa e no desafio de viabilizar as atividades de $\mathrm{EaD}$ para os alunos, utilizando recursos próprios e tornando o momento excepcional com aprendizagens significativas e que contribuíssem para a continuidade do ensino e da integração entre docentes para trocas consideráveis de experiências. O último e quarto ponto, que se faz importante apontar, foi o envolvimento dos estudantes que conseguiram acesso nas atividades, na partilha de experiências online, no diálogo científico e intelectual nas redes sociais, no uso das mídias sociais para um fim educativo e na postura dos mesmos durante a abordagem das aulas e dos conteúdos nos aplicativos e no SIGAA.

\section{Considerações Finais}

A Pandemia mundial de COVID-19 mobilizou a sociedade para atividades em todos os setores remotamente. O setor educacional não foi diferente e munidos de legislações, as instituições movimentaram suas estruturas para ofertar a $\mathrm{EaD}$, os professores para instrumentalizar-se de metodologias didático-pedagógica acessíveis e os estudantes para o acesso às TDIC. Porém, a falta de acesso à internet, tanto por educadores como por educandos e a falta de recursos tecnológicos levaram a não efetivação da $\mathrm{EaD}$, no IFAM - Campus Parintins. As estatísticas institucionais no fechamento do primeiro bimestre levaram a índices inferiores a $60 \%$ de acessos nas aulas, mesmo que alguns campus apuraram resultados acima desses percentuais, como ocaso de Parintins.

Considerando o exposto e a Portaria $n^{\circ} 05$ (Ifam, 2020e) que trata da reorganização do Calendário Escolar e da possibilidade de cômputo de atividades não presenciais para fins de cumprimento da carga horária mínima anual, em razão de COVID-19, o IFAM defende uma educação pública, gratuita, equitativa, inclusiva, democrática e de qualidade social destinada a todas as pessoas envolvidas em sua rede de atuação. Desta forma, cientes das disparidades de acesso a serviços básicos e das desigualdades sociais existentes, e após comprovação efetiva 
no exercício das atividades não presenciais realizadas para conclusão do primeiro bimestre de 2020.1, o IFAM optou por interromper as ações educacionais não presenciais nos cursos da Educação Profissional Técnica de Nível Médio (EPTNM) e da Graduação. O IFAM avaliou que o direito à educação, em termos de acesso, de permanência e de qualidade dos processos de ensino-aprendizagem, ficava prejudicado, deixando grande parte de seus estudantes em situação precária e desigual, caso fosse dado continuidade às políticas de EaD, validando atividades remotas como dias letivos e sem flexibilização do calendário escolar.

A IES tem ciência que grande parte dos discentes não tinham sequer infraestrutura básica adequada e que várias ações estavam sendo realizadas nos diversos campi, como apoio nas ações de cuidado e distribuição de alimentos dirigidos originalmente a alimentação escolar e atuação como amparo nas plantações dos agricultores infectados de COVID-19. Desta forma, no momento de COVID-19, em que as desigualdades sociais e educacionais tendem a se aprofundar, a resposta do IFAM, é manter o comprometimento com o direito à educação e com a defesa dos princípios constitucionais que garantem uma educação pública, gratuita, de qualidade e que não seja excludente, mas inclusiva e equitativa.

Salienta-se que no IFAM, a Resolução $\mathrm{n}^{\circ} 14$ (Ifam, 2020f) autorizou a suspensão Parcial do Calendário acadêmico de 24 de abril até 31 de maio de 2020, bem como estipulou que as atividades que ficaram mantidas seriam a formação de professores em cursos para atuação em EaD e a manutenção de atividades essenciais entre outras determinações. Sabe-se que as discussões empreendidas neste texto não encerram o debate aqui exposto, mas serviram como um espaço para refletir sobre o momento atual, as resistências, os desafios e os avanços da EaD na EPT. Contudo, dada a relevância do tema e das limitações deste estudo, espera-se que esta leitura instigue novas investigações, em especial, acerca do ensino híbrido em tempos de pandemia.

\section{Referências}

Abed - Associação Brasileira de Educação a Distância (2008). O que é educação a distância? São Paulo: ABED. Acesso em 02 abril, 2020, em http://www.abed.org.br/site/pt/faq/.

Alves, JRM (2007). A educação a distância no Brasil. Instituto de Pesquisas Avançadas em Educação. Brasil. 
Alves, JRM (2009). A história da EaD no Brasil. In: Litto, F. M. \& Formiga, M. Educação a distância: o estado da arte. 1 ed. São Paulo: Pearson.

Assumpção, CM (2019). Quais são os recursos de EAD que estão despontando no horizonte? In: ABED - Associação Brasileira de Educação a Distância. Censo EAD.BR 2018. Relatório analítico da aprendizagem a distância no Brasil. Curitiba: InterSaberes.

Azevedo, W (2000). Panorama atual da educação a distância no Brasil. Acesso em 02 abril, 2020, em http://www.aquifolium.com.br/educacional/artigos/.

Brasil (1996). Lei $n^{\circ}$ 9.394, de 20 de dezembro de 1996. Estabelece as Diretrizes e Bases da Educação Nacional. Acesso em 02 abril, 2020, em http://www.planalto.gov.br/ccivil_03/leis/19394.htm.

Brasil (2004). Portaria $n^{o}$ 4.059, de 10 de dezembro de 2004. Acesso em 03 abril, 2020, em http://portal.mec.gov.br/sesu/arquivos/pdf/nova/acs_portaria4059.pdf.

Brasil (2005). Decreto $N^{o} 5.622$, de 19 de dezembro de 2005. Regulamento o art. 80 da lei $\mathrm{n}^{\circ}$ 9.394, de 20 de dezembro de 1996, que estabelece as diretrizes e bases da educação nacional. Acesso em 02 abril, 2020, em http://www.planalto.gov.br/ccivil_03/_Ato20042006/2005/Decreto/D5622.htm.

Brasil (2008). Lei $n^{\circ} 11.788$, de 25 de setembro de 2008. Dispõe sobre o estágio de estudantes; altera a redação do art. 428 da Consolidação das Leis do Trabalho - CLT, aprovada pelo Decreto-Lei $\mathrm{n}^{\circ} 5.452$, de $1^{\circ}$ de maio de 1943, e a Lei ${ }^{\circ} 9.394$, de 20 de dezembro de 1996; revoga as Leis $n^{\text {os }} 6.494$, de 7 de dezembro de 1977, e 8.859, de 23 de março de 1994, o parágrafo único do art. 82 da Lei n ${ }^{\circ}$ 9.394, de 20 de dezembro de 1996, e o art. $6^{\circ}$ da Medida Provisória ${ }^{\circ}$ 2.164-41, de 24 de agosto de 2001; e dá outras providências. Acesso em 03 abril, 2020, em http://www.planalto.gov.br/ccivil_03/_ato20072010/2008/lei/111788.htm.

Brasil (2012). Resolução $n^{\circ}$ 6, de 20 de setembro de 2012. Define Diretrizes Curriculares Nacionais para a Educação Profissional Técnica de Nível Médio. Acesso em 03 abril, 2020, 
em http://portal.mec.gov.br/index.php?option=com_docman\&view=download\&alias=11663rceb006-12-pdf\&category_slug=setembro-2012-pdf\&Itemid=30192.

Brasil (2015). Instituto Nacional de Estudos e Pesquisas Educacionais Anísio Teixeira. Plano Nacional de Educação PNE 2014-2024: Linha de Base. Brasília, DF: Inep.

Brasil (2016). Catálogo Nacional de Cursos Técnicos. Acesso em 03 abril, 2020, em http://portal.mec.gov.br/publicacoes-para-professores/30000uncategorised/52031-catalogo-nacional-de-cursos-tecnicos.

Brasil (2017). Decreto $N^{\circ} 9.057$, de 25 de maio de 2017. Regulamento o art. 80 da Lei ${ }^{\circ}$ 9.394, de 20 de dezembro de 1996, que estabelece as diretrizes e bases da educação nacional. Acesso em 02 abril, 2020, em http://www.planalto.gov.br/ccivil_03/_Ato20152018/2017/Decreto/D9057.htm\#art24.

Brasil (2018). Portaria $n^{\circ} 1.428$, de 28 de dezembro de 2018. Dispõe sobre a oferta, por Instituições de Educação Superior - IES, de disciplinas na modalidade a distância em cursos de graduação presencial. Acesso em 14 abril, 2020, em http://www.in.gov.br/materia//asset_publisher/Kujrw0TZC2Mb/content/id/57496468/do1-2018-12-31-portaria-n-1-428-de28-de-dezembro-de-2018-57496251.

Brasil (2019). Portaria $N^{o} 2.117$, de 6 de dezembro de 2019. Dispõe sobre a oferta de carga horária na modalidade de Ensino a Distância - EaD em cursos de graduação presenciais ofertados por Instituições de Educação Superior - IES pertencentes ao Sistema Federal de Ensino. Acesso em 14 abril, 2020, em http://www.in.gov.br/en/web/dou/-/portaria-n-2.117de-6-de-dezembro-de-2019-232670913.

Brasil (2020a). Portaria $N^{o} 343$, de 17 de março de 2020. Dispõe sobre a substituição das aulas presenciais por aulas em meios digitais enquanto durar a situação de pandemia do Novo Coronavírus - COVID-19. Acesso em 02 abril, 2020, em http://www.in.gov.br/en/web/dou//portaria-n-343-de-17-de-marco-de-2020-248564376.

Brasil (2020b). Medida Provisória $N^{o}$ 934, de $1^{o}$ de abril de 2020. Estabelece normas excepcionais sobre o ano letivo da educação básica e do ensino superior decorrentes das 
medidas para enfrentamento da situação de emergência de saúde pública de que trata a Lei $\mathrm{n}^{\circ}$ 13.979, de 6 de fevereiro de 2020. Acesso em 02 abril, 2020, em http://www.in.gov.br/en/web/dou/-/medida-provisoria-n-934-de-1-de-abril-de-2020250710591.

Brasil (2020c). CNE aprova diretrizes para escolas durante a pandemia. Acesso em 02 maio, 2020, em http://portal.mec.gov.br/index.php?option=com_content\&view=article\&id=89051\%3Acneaprova-diretrizes-para-escolas-durante-a-pandemia\&catid=12\&fbclid=IwAR0Im9WfdSFgf_TRg3v4Wd5IapGjuqKacjdbPBny6rWGbix2XagiD8IEC4.

Brasil (2020d). O que é educação a distância? Acesso em 02 abril, 2020, em http://portal.mec.gov.br/index.php?option=com_content\&view=article\&id=12823.

Brasil (2020e). Instrução normativa $n^{\circ} 19$, de 12 de março de 2020. Estabelece orientações aos órgãos e entidades do Sistema de Pessoal Civil da Administração Pública Federal SIPEC, quanto às medidas de proteção para enfrentamento da emergência de saúde pública de importância internacional decorrente do coronavírus (COVID-19). Acesso em 09 maio, 2020, em http://www.in.gov.br/en/web/dou/-/instrucao-normativa-n-19-de-12-de-marco-de-2020247802008.

Brasil (2020f). Coronavírus: monitoramento nas instituições de ensino. 2020f. Acesso em 09 maio, 2020, em http://portal.mec.gov.br/coronavirus/.

Camacho, ACLF et al. (2020). A tutoria na educação à distância em tempos de COVID-19: orientações relevantes. Research, Society and Development, 9, (5), 1-12.

Castaman, AS \& Rodrigues, RA (2020). Educação a Distância na crise COVID - 19: um relato de experiência. Research, Society and Development, Itabira/MG, 9, (6), 1-26.

Churkin, OM (2020). Educação à distância um marco civilizatório, um olhar holístico da pedagogia: sinergia e reflexões na conectividade em tempos de COVID-19. Brazilian Jounal of Health Review, Curitiba, 3, (2), 3178-96. 
Gil, AC (2007). Como elaborar projetos de pesquisa. 4.ed. São Paulo: Atlas.

Gil, AC (2008). Métodos e técnicas de pesquisa social. 6.ed. São Paulo: Atlas.

Ifam. (2020a). Ordem de serviço conjunta $N^{o} 01$ - PROEN/ PPPGI/PROEX/, de 17 de março de 2020. Ifam - Instituto Federal de Educação, Ciência e Tecnologia do Amazonas Acesso em 09 maio, 2020, em http://www2.ifam.edu.br/noticias/ordem-de-servico-conjuntano-01-2013-proen-pppgi-proex-de-17-de-marco-de-2020.

Ifam. (2020b). Portaria $n^{o}$ 472-GR/IFAM, de 16 de março de 2020. Ifam - Instituto Federal de Educação, Ciência e Tecnologia do Amazonas Acesso em 09 maio, 2020, em http://www2.ifam.edu.br/noticias/nota-oficial-do-ifam-covid-19/Portaria_472.2020.pdf.

Ifam. (2020c). Portaria Conjunta $N^{o} 1$, de 17 de março de 2020. Acesso em 09 maio, 2020, em http://www2.ifam.edu.br/ifam-contra-o-coronavirus.

Ifam. (2020d). Portaria no 20 - PROEN/IFAM, de 03 de abril de 2020. Mimeo.

Ifam. (2020e). Portaria n ${ }^{o}$ 05.Portaría de 2020. Mimeo.

Ifam - Instituto Federal de Educação, Ciência e Tecnologia do Amazonas (2020f). Resolução $n^{o}$ 14-CONSUP/IFAM de 23 de abril de 2020. Acesso em 09 maio, 2020, em http://www2.ifam.edu.br/campus/cmc/Resolucaon14Proc.23443.006825202086SuspenderCal. Academico2Bimestre23.04.2020OFICIAL.pdf.

Ifam. (2020g). Portaria $N^{o}$ 19-PROEN/IFAM de 01 de abril de 2020, os critérios para a validação das atividades de ensino, para fins de manutenção do calendário acadêmico. Mimeo.

Ifam. Campus Parintins (2020). [Dados de acesso dos estudantes as Plataformas Digital em meio a pandemia]. Whatsapp: [CGE/IFAM].17 abr. 1 mensagem de Whatsapp. 
Lombardi, VV et al. (2010). EaD como ferramenta de acesso à informação biomédica através da pesquisa bibliográfica. In: XVI SEMINÁRIO NACIONAL DE BIBLIOTECAS

UNIVERSITÁRIAS, Rio de Janeiro. Anais... 2010, Rio de Janeiro, p. 1-10.

Maia, C \& Mattar, J. (2007). ABC da EaD: a Educação a Distância hoje. São Paulo: Pearson.

Mesquita, D, Piva Jr, D \& Gara, EBM (2014). Ambiente virtual de aprendizagem: conceitos, normas, procedimentos e práticas pedagógicas no ensino a distância. 1 ed. São Paulo: Érica.

Moran, JM, Masetto, MT \& Behrens, MA (2008). Novas tecnologias e mediação pedagógica. 14.ed. Campinas, SP: Papirus.

Nunes, LB (1994). Noções de Educação a Distância. Revista de educação a distância.

Brasília, 4/5, 7-25.

Oliveira, HV. \& Souza, FS (2020). Do conteúdo programático ao sistema de avaliação: reflexões educacionais em tempos de pandemia (COVID-19). Boca-Boletim de Conjuntura, Boa Vista, 2(5), 1-11.

Pacheco, EM (2020). Desvendando os institutos federais: identidade e objetivos. Educação Profissional e Tecnológica em Revista, Vitória, 4(1), 1-22.

Pereira, AS, Shitsuka, DM, Parreira, FJ \& Shitsuka, R. (2018). Metodologia da pesquisa científica. [e-book]. Santa Maria. Ed. UAB/NTE/UFSM. Disponível em: https://repositorio.ufsm.br/bitstream/handle/1/15824/Lic_Computacao_MetodologiaPesquisa-Cientifica.pdf?sequence $=1$.

Santos, P (2010). Secretaria de Educação a Distância (SEED). Acesso em 02 abril, 2020, em <http://www.moodle.ufba.br/mod/forum/discuss.php?d=11962>.

Tostes, A \& Melo Filho, H (2020). Quarentena: reflexões sobre a pandemia e depois. 1 ed. Bauru: Canal 6. 
Unesco. (2020). Suspensão das aulas e resposta à COVID-19. Unesco - Organização das Nações Unidas para a Educação, a Ciência e a Cultura Acesso em 07 abril, 2020, em https://pt.unesco.org/covid19/educationresponse.

Vieira, LFK et al. (2016). EaD na contabilidade: uma análise de sua efetivação de uso no curso de Ciências Contábeis da Universidade Federal do Rio Grande do Sul. Revista Gual, Florianópolis, 9 (2): 27- 48.

\section{Porcentagem de contribuição de cada autor no manuscrito}

Ana Sara Castaman - 50\%

Elenice Szatkoski - 50\% 